\title{
Immunostaining with D2-40 improves evaluation of lymphovascular invasion, but may not predict sentinel lymph node status in early breast cancer
}

\author{
Anna V Britto1 ${ }^{1}$ André A Schenka ${ }^{2}$, Natália G Moraes-Schenka², \\ Marcelo Alvarenga ${ }^{3}$, Júlia Y Shinzato ${ }^{3}$, José Vassallo*2 and Laura S Ward ${ }^{1}$
}

\begin{abstract}
Address: ${ }^{1}$ Molecular Genetics of Cancer Laboratory, Department of Internal Medicine, School of Medical Sciences, State University of Campinas (Unicamp), São Paulo, Brazil, ${ }^{2}$ Laboratory of Investigative and Molecular Pathology (CIPED), School of Medical Sciences, State University of Campinas (Unicamp), São Paulo, Brazil and ${ }^{3}$ Department of Obstetrics and Gynecology, School of Medical Sciences State University of Campinas (Unicamp), São Paulo, Brazil

Email: Anna V Britto - avbritto@yahoo.com; André A Schenka - schenka@hotmail.com; Natália G Moraes-

Schenka - nataliamoraes@hotmail.com; Marcelo Alvarenga - lape@caism.unicamp.br; Júlia Y Shinzato - juliashinzato@uol.com.br; José Vassallo* - vassallomeister@gmail.com; Laura S Ward - ward@fcm.unicamp.br

* Corresponding author
\end{abstract}

Published: 8 April 2009

BMC Cancer 2009, 9:109 doi:10.1186/147|-2407-9-109
Received: 30 August 2008

Accepted: 8 April 2009

This article is available from: http://www.biomedcentral.com//47/-2407/9//09

(c) 2009 Britto et al; licensee BioMed Central Ltd.

This is an Open Access article distributed under the terms of the Creative Commons Attribution License (http://creativecommons.org/licenses/by/2.0), which permits unrestricted use, distribution, and reproduction in any medium, provided the original work is properly cited.

\begin{abstract}
Background: Sentinel lymph node (SLN) biopsy is a widely used diagnostic procedure in the management of early breast cancer. When SLN is free of metastasis, complete axillary dissection may be skipped for staging in clinically No patients, allowing a more conservative procedure. Histological tumor features that could reliably predict SLN status have not yet been established. Since the degree of tumor lymphangiogenesis and vascularization may theoretically be related to the risk of lymph node metastasis, we sought to evaluate the relationship between lymph vessel invasion (LVI), lymphatic microvascular density (LVD), microvascular density (MVD) and VEGF-A expression, with SLN status and other known adverse clinical risk factors.
\end{abstract}

Methods: Protein expression of D2-40, CD34, and VEGF-A was assessed by immunohistochemistry on paraffin-embedded sections of primary breast cancer specimens from 92 patients submitted to SLN investigation. The presence of $L V I$, the highest number of micro vessels stained for D2-40 and CD34, and the protein expression of VEGF-A were compared to SLN status, clinicopathological features and risk groups.

Results: LVI was detected in higher ratios by immunostaining with D2-40 $(p<0.000 \mathrm{I})$, what would have changed the risk category from low to intermediate in four cases $(4.3 \%)$. There was no association between LVI and other angiogenic parameters determined by immunohistochemistry with SLN macrometastases, clinical features or risk categories.

Conclusion: Assessment of LVI in breast carcinoma may be significantly increased by immunostaining with D2-40, but the clinical relevance of altering the risk category using this parameter may not be advocated according to our results, neither can the use of LVI and LVD as predictors of SLN macrometastasis in early breast cancer. 


\section{Background}

Breast cancer is the most frequent neoplasm in women in several countries, including Brazil. In the last decades, detection of disease in earlier clinical stages has improved prognosis, however five-year disease-free survival of breast cancer presenting with $\mathrm{T} 1$ to $3, \mathrm{N0}-1$, and M0 staging remains at about $72 \%$ [1]. For this reason, continuing efforts to establish reliable prognostic markers are made.

Malignant neoplasms are angiogenesis-dependent [2]. The prognostic value of the tumor microvascular density (MVD) in breast cancer has been examined in several studies, with correlations with tumor recurrence, diseasefree or overall survival [3-14]. Some discrepancies detectable on the subject may be explained by differences in patients' selection (age, menopausal status, tumor type, tumor size, adjuvant treatment, follow-up interval, number of patients included in each study), and in material and methods used (antibody's specificity, methods used to assess MVD). Considering meta-analysis results, significant evidence for the prognostic value of MVD in breast cancer was detected, however it was weak [15]. Vascular invasion around the tumor has been also considered an adverse risk factor in node-negative breast carcinoma [16]. It has been recently shown that assessing lymphovascular invasion (LVI) is related with other features of aggressiveness of breast cancer, as high proliferation index and low hormonal receptor [17]. In spite of the number of publications on the subject, the value of LVI and other angiogenesis markers in early breast carcinoma has not been sufficiently explored in part because the lack of reliable antibodies. The use of D2-40 in tumor pathology to detect lymphatic vessels is growing, but some controversy is expected because the experience in its use is quite recent. In the present study it was our purpose to evaluate the feasibility of vascular invasion assessed by hematoxilin-eosin (H\&E) and by immunostaining with D2-40, as well as LVD, MVD and VEGF-A expression in early breast carcinoma, and its correlation to sentinel lymph node (SLN) status and to other clinicopathological parameters.

\section{Methods}

Consecutive female patients diagnosed with early breast carcinoma and submitted to SLN examination were selected from 2004 to 2006 at the Women's Hospital of the State University of Campinas Medical School, Unicamp, São Paulo, Brazil. The present study was performed with the approval of the Committee of Ethics in Research of our institution, and was carried out in compliance with the Helsinki Declaration. Ninety-two cases were morphologically reanalyzed, both tumor and SLN. Medical records were revised; patient's age, tumor size, axillary lymph node involvement, risk group, pathological staging of tumor and lymph nodes and clinical evaluation for metastasis ( $\mathrm{pT} \mathrm{pN} \mathrm{cM}$ ) were determined as markers of aggressiveness. Staging was based on the AJCC Cancer Staging Manual, 6th Edition (2002) [18]. Histologic grade was determined by the modified Nottingham classification, proposed by Elston \& Ellis [19]. Risk groups were classified according to Goldhirsh et al (2005) [16], as follows:

\section{Low risk}

Node negative AND all of the following features: pT $\leq 2$ $\mathrm{cm}$, AND histological grade 1, AND absence of peritumoral vascular invasion, AND HER2/neu gene neither overexpressed nor amplified, AND age $\geq 35$ years.

\section{Intermediate risk}

IF node negative AND at least one of the following features: pT $\geq 2 \mathrm{~cm}$, OR histological grade $2-3$, OR presence of peritumoral vascular invasion, OR HER2/neu gene overexpressed or amplified, OR age $<35$ years. OR IF less than four nodes are positive, AND HER2/neu gene neither overexpressed nor amplified.

\section{High risk}

One to three nodes positive AND Her2/neu gene overexpressed or amplified, OR four or more nodes positive.

\section{Sentinel Node (SLN)}

SLNs were detected using a combination of radioactive colloid and Patent blue V. Three hours before surgery, 0.2 $\mathrm{ml}$ radioactive tracer (dextran $\mathrm{mCi} 99 \mathrm{mTc}$-labelled) was injected subdermally at the tumor site. Twenty to $30 \mathrm{~min}$ utes afterwards, lymphatic scintillography was performed to localize SLNs. The skin overlying the node was marked with permanent ink. During the surgery, a blue dye $(2 \mathrm{ml}$, $50 \mathrm{mg} / \mathrm{ml}$ ) was applied at the lesion site by a subdermal injection. SLNs were then detected simultaneously by a hand-held gamma ray detecting probe and visual control. All surgically removed SLNs underwent intraoperative cyto- (imprints) and histopathological examination. Gross processing of the nodes consisted of serial sectioning in 1-2 mm thick slices, which were fixed in $10 \%$ formalin and embedded in paraffin. They were then microscopically evaluated in serial H\&E stained sections at intervals of $150 \mu \mathrm{m}$ [20]. In negative cases, two slide samples were additionally stained with an anti-pancytokeratin antibody (AE1/AE3, Dako, Carpenteria, CA, USA; $1: 200)$. As the clinical value of isolated neoplastic cells and the presence of micrometastasis $(0.2-2 \mathrm{~mm})$ is still controversial for decision taking, in the present study SLN were considered positive for statistical analysis only when they contained tumor foci greater than $2 \mathrm{~mm}$ (macrometastasis). 


\section{Immunohistochemistry}

Briefly, two levels of $4-\mu \mathrm{m}$ thick sections were obtained, placed on silanized slides, deparaffinized in xylene and rehydrated. Endogenous peroxidase activity was quenched with 3\% hydrogen peroxide. Antigen retrieval was performed by heating slides in citrate buffer $(10 \mathrm{mM}$, $\mathrm{pH}$ 6.0) at $95^{\circ} \mathrm{C}$ for 30 minutes. The primary monoclonal antibodies used were mouse anti-human VEGF-A (CloneVG1, Dako, diluted at 1:100), CD34-Class II (Clone QBend-10, Dako, 1:50), D2-40 (Clone D2-40, Dako, 1:50), estrogen receptor (Clone 1D5, Dako, 1:150), progesterone receptor (Clone PGR636, Dako, 1:300), and HER-2/neu (Clone PN2A, Dako, 1:450). The Max Polymer Detection System (Novolink, Novocastra, Newcastle, UK) was used to reveal antigen-antibody reaction. Staining was achieved using 3,3-diamonobenzidine tetrahydrochlride (Sigma, St. Louis, MO, USA) and counterstaining using Mayer's hematoxilin. All reactions were performed using appropriate positive and negative controls.

All scores are represented by the mean of the two levels evaluated by immunohistochemistry. Immunostaining for hormone receptors were scored as negative or positive ( 0 and 2 vs 3 to 8 , according to Harvey et al, 1999) [21]. Immunostaining for HER-2/neu was scored as negative, $1+$ to $3+$, according to previously described parameters [22]. Cases scored as 2+ were additionally submitted to chromogenic "in situ" hybridization (CISH, Zymed's SpoT-Light ${ }^{\mathrm{R}}$ HER2CISH $^{\mathrm{TM}}$, Invitrogen, San Francisco, CA, USA), according to the manufacturer's instructions [23]. VEGF-A expression was scored based on extent or percentage of positive cells (0: negative; 1 : <25\%; 2: 26-50\%; 3; $51-75 \% ; 4:>75 \%)$ and staining intensity ( 0 : negative; 1 : weak; 2 : moderate; 3 : strong). The sum of both parameters resulted in a final VEGF-A score, which was then grouped into three categories: negative to weak (0-2), moderate (3-5) and strong (6-7) immunostaining.

\section{Microvessel density and vascular invasion assessment}

Blood and lymphovascular microvessel density were assessed independently by two observers, without knowledge of the patients' clinicopathologic data. Immunostained tumor sections were scanned at low magnification $(40 \times)$ and the three most densely vascular areas ("hot spots") were photographed at magnification $200 \times(0.74$ $\mathrm{mm}^{2}$ per field). Vessels stained by CD34 or D2-40 were counted using an image analysis software (Imagelab ${ }^{\circledR}$, version 2.4, São Paulo, Brazil). Tumor lymphatic vessel invasion was established when at least one neoplastic cell cluster was clearly visible inside a D2-40 positive lymph vessel according to Yamauchi et al, 2006 [24]. Tumor lymphatic invasion thus determined was compared with the one independently reported in $\mathrm{H} \& \mathrm{E}$ stains.

\section{Statistical analyses}

Statistical analysis was performed using the SAS System for Windows software (version 9.1.3). Associations were assessed using $2 \times 2$ or $2 \times \mathrm{n}$ contingency table analysis. The Fisher's exact test was used to examine relationship between VEGF-A expression and risk groups, pathological stage and SLN status, as well as clinicopathological features (tumor size, menopausal status, histological type, histological grade, pathological stage, estrogen and progesterone receptors, Her2/neu expression, vascular invasion on HE and on D2-40 stained slides) and sentinel node status. Multiple logistic regression analysis was used to evaluate the effect of microvascular density and vascular invasion markers, after adjusting for other potential confounders such as age and tumor size. Correlations between CD34 and D2-40 expression levels, as well as between these antibodies and VEGF-A expression groups were calculated using the linear Spearman's coefficient. Vascular invasion on H\&E and D2-40 staining were analyzed using the McNemar test. The Kappa value was calculated to assess inter-observer variability concerning VEGFA expression. The interclass correlation coefficient was determined to evaluate inter-observer variability concerning the expression of CD34 and D2-40. The significance level was set at $\mathrm{p}=0.05$ for all tests.

\section{Results}

Median age of patients was $55 \mathrm{y}$ (range 32-77 y). Twentythree patients were pre-menopausal and 69 menopausal. Stage of disease was I in 58 patients, II in 26 and III in 8. Tumor size presented a median of $12 \mathrm{~mm}$ (range $2-50$ $\mathrm{mm}$ ). Eighty cases corresponded to the ductal type, 5 were lobular and 7 of other types. Histological grade was I in 36 patients, II in 47 and III in 9.

SLN was positive in 31 patients (33.7\%), more frequently in pre-menopausal women $(52.1 \% v s .27 .5 \%$; $\mathrm{p}=0.03)$. Patients with positive SLN were significantly younger: median 53 y (range 33-68 y) vs 57 y (range 32-77 y; p = $0.013)$. Six patients were included in the low risk group $(6.5 \%), 73$ in the intermediate risk group (79.3\%) and 13 in the high risk group (14.2\%). Estrogen receptor status was positive in 77 patients and negative in 14. Progesterone receptor was positive in 76 patients and negative in 15. HER2/neu status was negative in 61 patients and positive (either $3+$ by immunohistochemistry or amplified by $\mathrm{CISH}$ ) in 29. In one patient it was not possible to assess ER and PR status; the same occurred in two patients related to HER2/neu status. (Lymph-)vascular invasion (LVI) was present in $6.5 \%$ (six patients) of the cases on H\&E slides and in 29.3\% (27 patients) on D2-40 stained sections. The difference between both methods of evaluation was significant (McNemar test: $\mathrm{p}<0.0001)$. When both methods of evaluation of LVI were compared to each other, an agreement ratio of $75 \%$ was found (Table 1 ). 
Table I: Correlation between evaluation of (lympho-)vascular invasion assessed by hematoxilin \& eosin (H\&E) staining and by immunohistochemistry using the D2-40 antibody

\begin{tabular}{|c|c|c|c|}
\hline \multirow[t]{2}{*}{ Vascular invasion assessed by $\mathrm{H} \& \mathrm{E}$} & \multicolumn{2}{|c|}{ Lymph vascular invasion assessed by immunostaining with D2-40 } & \multirow[t]{2}{*}{ Total } \\
\hline & Negative & Positive & \\
\hline Negative & 64 & 22 & 86 \\
\hline Positive & 1 & 5 & 6 \\
\hline Total & 65 & 27 & 92 \\
\hline
\end{tabular}

$75 \%$ agreement; there was no relation between both methods by the Fisher's exact test $(p=0.335)$; accordingly, the difference between both methods of assessing vascular invasion was significantly different by the McNemar test $(p<0.000 \mathrm{I})$

When both methods of evaluation of LVI were compared to SLN status, either grouping the number of positive SLN in $0 v s \geq 1$ (Table 2), or 0 and up to $3 v s \geq 4$ (Table 3), no significant correlation was found. When both methods of evaluation of LVI were compared to the three risk groups (Table 4), only evaluation by H\&E showed significant correlation to risk groups $(\mathrm{p}=0.04)$.

When patients' data were analyzed according to the presence $(n=28)$ and absence $(n=64)$ of LVI by either method, H\&E or D2-40, no correlation was found according to patients' age, tumor size, histological type or grade, MVD counts (CD34), LVD (D2-40), VEGF-A, HER-2/neu and hormonal receptor status, or to SLN status.

Immunostaining with D2-40 would have resulted in upgrade of risk group classification of four cases (4.3\%). Multiple logistic regression revealed a relationship between SLN status and tumor size $(\mathrm{p}=0.0012)$ and age $(p=0.013)$. There was no relationship between SLN status and all other clinicopathological variables: stage of the disease, hormonal receptor and HER2/neu status, vascular invasion (assessed by H\&E or D2-40), VEGF-A immunostaining, MVD, or LVD (Table 5), after adjusting for tumor size and age. There was no correlation between risk groups, LVD, MVD or VEGF-A expression. Spearman's coefficient between CD34, D2-40 and VEGF-A was low, reflecting lack of significant correlation. Her2/neu was not correlated to VEGF-A, CD34 and D2-40. The interclass correlation coefficient between two observers related to
CD34 and D2-40 were, respectively, 0.995 (CI95\% = $0.989-0.997)$ and $0.87(\mathrm{CI} 95 \%=0.63-0.90)$. Kappa value was $0.7154(\mathrm{CI} 95 \%=0.48-0.95)$.

\section{Discussion}

The presence of lymph node metastasis is one of the most important prognostic factors in breast cancer [25]. Our data showed that only younger age, pre-menopausal status (both parameters reflecting approximately the same biological phenomenon), and larger tumor size were related to SLN status, which is consistent with the known adverse influence of these parameters in defining risk groups, particularly in early breast cancer [26]. The present data support the value of performing immunostaining using the antibody D2-40 to significantly improve evaluation of LVI. This finding is in keeping with most studies which performed the comparison between assessments of LVI by H\&E and D2-40 stains [17,24,2730]. However, as neither method significantly improved predictability of SLN status in the current study, it is yet not possible to sustain the habitual use of D2-40 staining in the evaluation of risk categories.

In four of our cases $(4.3 \%)$, the immunohistochemical assessment of LVI would have changed the risk group of the patients from low to intermediate. However, the relevance of this upgrade for the management of the patient cannot be assured. It has been evidenced elsewhere that the presence of vascular invasion was significantly associated with poorer disease free survival both in the entire

Table 2: Correlation between (lympho-)vascular invasion and sentinel lymph node (SLN) status

\begin{tabular}{lcccc}
\hline SLN & \multicolumn{2}{c}{ Vascular invasion assessed by H\&E } & \multicolumn{2}{c}{ Lymph vascular invasion assessed by immunostaining with D2-40 } \\
\cline { 2 - 5 } & Negative & Positive & Negative & Positive \\
\hline Negative & 57 & 4 & 44 & 17 \\
Positive & 29 & 2 & 21 & 10 \\
Total & 86 & 6 & 65 & 27 \\
\hline P values* & & 0.090 & & 0.376 \\
\hline
\end{tabular}

* Fisher's exact test 
Table 3: Correlation between four or more positive and negative + up to three sentinel lymph nodes (SLN) and status of (lympho)vascular invasion

\begin{tabular}{lcccc}
\hline SLN & \multicolumn{2}{c}{ Vascular invasion assessed by H\&E } & Lymph vascular invasion assessed by immunostaining with D2-40 \\
\cline { 2 - 5 } & Negative & Positive & Negative & Positive \\
\hline Negative or $<4$ positive & 80 & 6 & 60 & 26 \\
$\geq 4$ positive & 6 & 0 & 5 & 1 \\
Total & 86 & 6 & 65 & 27 \\
\hline P values* & 0.103 & & 0.543
\end{tabular}

* Fisher's exact test

group of patients analyzed, and when only the group presenting positive non-sentinel lymph node was considered. However, only the results obtained with D2-40, but not on H\&E stain, were statistically significant [29]. The opposite has been stated in another study, in which the authors referred a concordance of $78.2 \%$ between LVI in H\&E and with D2-40 (similar to ours, 75\%). Only the values obtained on $\mathrm{H} \& \mathrm{E}$ stained sections were correlated with positive SLN [31]. In a recent report, when LVI was correlated with the presence of micro and macrometastases in axillary lymph nodes, only the evaluation on $\mathrm{H} \& \mathrm{E}$ stains was significantly associated with the presence of macrometastasis in SLN [17]. These differences raise the issue that the increase in sensitivity in LVI detection by immunohistochemistry might not be associated with clinically relevant impact, meaning that only higher degrees of vascular invasion easily detected on $\mathrm{H} \& \mathrm{E}$ stains are important. The practical value of utilizing the presence of LVI to predict SLN status could also be questioned, first because SLN evaluation does not imply a major surgical risk for the patient. In addition, most cases are diagnosed in a small sample of the tumor, and the absence of LVI in the original slides would not preclude SLN evaluation [32]. Also, even in those studies which demonstrate correlation between the presence of LVI and lymph node status present a percentage of discordance, a fact that will make it advisable to stick to the actual standardized procedures. The significance shown herein between vascular invasion assessed by $\mathrm{H} \& \mathrm{E}$ and risk categories is borderline and might not correspond to a consistent biologic fact, as all of the 13 cases placed in the high risk group showed negative SLN.

Another issue evidenced by the present findings is the contradiction of the expected SLN colonization by tumor cells, as they should be transported by the invaded peritumoral lymphatic vessels. A parallel verification could help to explain this finding: neoplastic involvement of nonSLN is not invariably present in patients with positive SLN [33]. Then, it could be argued that the simple presence of foci of neoplastic cells in more proximal regions of the lymphatic flow does not necessarily imply in their capability of escaping defense mechanisms, which may prevent their spread to the next step.

Assessment of vascular invasion in breast cancer is not taken into account in a widely used prognostic index, but it was included as a parameter in grouping patients with different risks, using H\&E stains [16,32]. Considering the above data, it might be important to reevaluate the reliability of including the assessment of LVI by immunohistochemistry using the antibody D2-40 in the prognostic index in large international trials, before using this method individually, which could be hazardous for the patient by overestimating the risk category. Such procedure is technically viable and would allow the comparison of data from reports in which only conventionally stained slides to detect vascular invasion have been used

Table 4: Correlation between the three risk groups and status of (lympho-) vascular invasion

\begin{tabular}{lcccc}
\hline Risk groups $^{a}$ & \multicolumn{2}{c}{ Vascular invasion assessed by H\&E } & \multicolumn{2}{c}{ Lymph vascular invasion assessed by immunostaining with D2-40 } \\
\cline { 2 - 5 } & Negative & Positive & Negative & Positive \\
\hline Low & 24 & 1 & 15 & 9 \\
Intermediate & 49 & 5 & 41 & 9 \\
High & 13 & 0 & 65 & 3 \\
Total & 86 & 6 & & 27 \\
\hline P values* & & 0.040 & & 0.221 \\
\hline
\end{tabular}

* Fisher's exact test; a: according to Goldhirsh et al, 2005 [ref. \# [16]] 
Table 5: Correlation between sentinel lymph node (SLN) status and microvascular density (MVD), lymphovascular density (LVD) and intensity of VEGF-A

\begin{tabular}{|c|c|c|c|c|c|}
\hline Marker & & All patients & SLN + & SLN - & $p$ values* \\
\hline \multirow[t]{3}{*}{ VEGF-A $^{a}$} & Negative and weakly positive & 37 & 13 & 24 & 0.32 \\
\hline & Moderately positive & 25 & 12 & 13 & \\
\hline & Strongly positive & 30 & 6 & 24 & \\
\hline MVD (CD34) & & $79(24-162)$ & $79(30-160)$ & $81(24-162)$ & 0.78 \\
\hline LVD (D2-40) & & $7(0-22)$ & $8(0-22)$ & $7(1-20)$ & 0.73 \\
\hline
\end{tabular}

* adjusted for tumor size and age; a: values correspond to the number of patients in each group; b: values correspond to median vessel count; range is in parenthesis.

[34-36]. For the sake of consistency, the topography in which LVI is searched should be considered the border of neoplasia, as data on the lymphangiogenesis in inner areas of the tumor and its possible relevance for prognosis is a matter of debate, perhaps because of differences in the markers used $[24,31,37]$. Quantification of vascular invasion around the tumor should also be evaluated, as this parameter could reflect more properly the likelihood of dissemination of the disease, as suggested before [36]. In other words, only pronounced vascular infiltration, rather than focal or sparse, could more likely suggest that tumor cells have acquired the potential to nest at distance.

For this purpose, D2-40 seems a good marker for lymphatic vessels, in spite of the possible pitfalls in interpretation of its reactivity. Rabban \& Chan (2008) suggested that p63 should be simultaneously used to stain myoepithelial cells when it renders difficult to distinguish between lymphangiovascular invasion and stromal myoepithelial cells in close relation to neoplastic cells [38]. Arnaout-Alkarain et al (2007) have used anti-CD31 to assist decision taking in cases with discordant results between LVI assessment with D2-40 and H\&E [27]. It has been also suggested that double staining using D2-40 in conjunction with proliferation marker Ki-67 should be preferred to avoid misinterpretation of LVI [39]. It should be kept in mind that the opposite can occur. In cases of minimal vascular invasion on $\mathrm{H} \& \mathrm{E}$ stains, further sections obtained for immunohistochemistry may not represent the same area of vascular invasion, resulting negative [17].

Our data demonstrated no association between MVD, LVD, and VEGF-A protein expression with SLN status and other clinicopathological features. Lack of relationship between markers of angiogenesis and clinicopathological features has been observed in other studies, but most reports have shown prognostic value of increased MVD and/or presence of LVI [12,24,28-31,40-44]. In additional studies, however, multivariate analysis has eliminated the prognostic value of angiogenic parameters [27,37]. The reason for the discrepancy between our results and other reports seems not to be related to selection bias, as we have studied a well defined group of patients, using the same clinical management protocol. We also used sensitive markers and well established techniques to determine MVD and LVD [45-47]. Moreover, the concordance rate between the two observers was satisfactory. However, unexpected drawbacks, such as inadequacy of antigen preservation, or differences due to dissimilar sources of antibodies might have accounted for this divergence.

The lack of correlation between LVD and SLN status also seems in opposition to the reasonable concept that the more vessels are around a tumor, the more likely it is to metastasize. However, in this respect we are dealing with the complex mechanisms of circulation and nesting of neoplastic cells, which might not be properly evaluated by the static methods used herein.

\section{Conclusion}

The data presented herein support the value of assessing LVI by immunohistochemistry using D2-40, in increasing the ratio of positive cases. It may be suggested that this parameter should be included in the evaluation of risk groups in patients with early breast cancer, in order to add a more reproducible parameter to compare different trials, and to determine in which extent this enhancement in sensitivity of the method will reveal clinical relevance. For now, the evidences from our study do not allow us to advocate the use of LVI and MVD or LVD as predictors of SLN invasion in breast cancer.

\section{Abbreviations}

CD: cluster of differentiation; CISH: chromogenic in situ hybridization; H\&E: hematoxilin and eosin; LVD: lymphatic microvascular density; LVI: lymph vessel invasion; MVD: microvascular density; SLN: sentinel lymph node; VEGF-A: vascular endothelial growth factor.

\section{Competing interests}

The authors declare that they have no competing interests.

\section{Authors' contributions}

AVB and LSW designed and participated in all steps of the study. AAS and JV participated in the analysis of immunohistochemical data, in statistical analysis and discussion 
of the results. NGMS and MA reviewed all histopathological slides. JYS proceeded surgeries and follow up of patients. All authors read and approved the final version manuscript.

\section{Acknowledgements}

JV and LWS are researchers of the Conselho Nacional de Desenvolvimento Científico e Tecnológico (CNPq, Brazil). The present study was supported with grants provided by the Fundação de Amparo à Pesquisa do Estado de São Paulo (FAPESP) and by the Fundo de Apoio ao Ensino, Pesquisa e Extensão (FAEPEX, Unicamp).

\section{References}

I. Adjuvant Breast Cancer Trials Collaborative Group: Polychemotherapy for early breast cancer: results from the International Adjuvant Breast cancer Chemotherapy Randomized Trial. J Natl Cancer Inst 2007, 99:506-5I5.

2. Gasparini G: Clinical significance of determination of surrogate markers of angiogenesis in breast cancer. Crit Rev Oncol Hematol 200I, 37:97-II4.

3. Weidner N, Semple JP, Welch WR, Folkman J: Tumor angiogenesis and metastasis-correlation in invasive breast cancer. $N$ Engl J Med 1991, 324:I-8.

4. Ogawa Y, Chung YS, Nakata B, Takatsuba S, Maeda K, Sawada T, Kato Y, Yoshikawa K, Sakurai M, Sowa M: Microvessel quantification in invasive breast cancer by staining for factor VIII-related antigen. $\mathrm{Br}$ J Cancer I995, 71:297-301.

5. Simpson JF, Ahn C, Battifora H, Esteban JM: Endothelial area as a prognostic indicator for invasive breast carcinoma. Cancer 1996, 77:2077-2085.

6. Martin L, Green B, Renshaw C, Lowe D, Rudland P, Leinster SJ, Winstanley ]: Examining the technique of angiogenesis assessment in invasive breast cancer. $\mathrm{Br}$ J Cancer 1997, 76: 1046-1054.

7. Gasparini G, Toi M, Verderio P, Ranieri G, Dante S, Bonoldi E, Boracchi $P$, Fanelli M, Tominaga T: Prognostic significance of $p 53$, angiogenesis, and other conventional features in operable breast cancer: subanalysis in node-positive and node-negative patients. Int I Oncol | 998, I 2: I I I7-I III25.

8. De Placido S, Carlomagno C, Ciardello F, de Laurentiis M, Pepe S, Ruggiero A, Tortora G, Panico L, D'Antonio A, Pettinato G, Petrella G, Bianco AR: Measurement of neovascularization is an independent prognosticator of survival in node-negative breast cancer patients with long-term follow-up. Clin Cancer Res 1999 5:2854-2859.

9. Kumar S, Ghellal A, Li C, Byrne G, Haboubi N, Wang JM, Bundred N: Breast carcinoma:vascular density determined using CD 105 antibody correlates with tumor prognosis. Cancer Res 1999 59:856-61.

10. Hansen S, Grabau DA, Sorensen FB, Bak M, Vach W, Rose C: Vascular grading of angiogenesis:prognostic significance in breast cancer. Br J Cancer 2000, 82:339-347.

II. Tsutsui S, Kume M, Era S: Prognostic value of microvessel density in invasive ductal carcinoma of the breast. Breast Cancer 2003, 10:312-319.

12. Schoppmann FS, Bayer G, Aumayer K, Taucher S, Geleff S, Rudas M, Kubista E, Hausmaninger H, Samonigg H, Gnant M, Jakesz R, Horvat R, Austrian Breast and Colorectal Cancer Study Group: Prognostic value of lymphangiogenesis and lymphovascular invasion in invasive breast cancer. Annals Surg 2004, 240:306-3I2.

13. Nakamura Y, Yasuoka H, Tsujimoto M, Imabun S, Nakahara M, Nakao K, Nakamura M, Mori I, Kakudo K: Lymph vessel density correlates with nodal status, VEGF-A-C, expression and prognosis in breast cancer. Breast Cancer Res Treat 2005, $91: 125-132$

14. Mohammed RA, Green A, El-Shikh S, Paish EC, Ellis IO, Martin SG: Prognostic significance of vascular endothelial cell growth factors-A, $C$ and $D$ in breast cancer and their relationship with angio and lymphangiogenesis. $\mathrm{Br} J$ Cancer 2007, 96:1092-1100

15. Uzzan B, Nicolas P, Cucherat M, Perret GY: Microvessel density as a prognostic factor in women with breast cancer: a systematic review of the literature and meta-analysis. Cancer Res 2004, 64:294I-2955.
16. Goldhirsch A, Glick JH, Gelber RD, Coates AS, Thurlimann B, Senn $\mathrm{H}$, Panel members: Meeting highlights: international expert consensus on the primary therapy of early breast cancer 2005. Ann Oncol 2005, 16:1569-1583.

17. Marinho VF, Metze K, Sanches FS, Rocha GF, Gobbi H: Lymph vascular invasion in invasive mammary carcinomas identified by the endothelial lymphatic marker D2-40 is associated with other indicators of poor prognosis. BMC Cancer 2008, 8:64.

18. Greene FL, Page DL, Fleming ID, Fritz AG, Balch CM, Haller DG Morrow M: Breast. In AJCC Cancer Staging Manual 6th edition. Edited by: Greene FL, Page DL, Fleming ID, Fritz AG, Balch CM, Haller DG, Morrow M. New York: Springer; 2002:223-240.

19. Elston CW, Ellis IO: Pathological prognostic factors in breast cancer. I. The value of histological grade in breast cancer: experience from a large study with long-term follow-up. Histopathology 1991, 19:403-410.

20. Cserni G: Evaluation of sentinel lymph nodes in breast cancer. Histopathology 2005, 46:697-706.

21. Harvey JM, Clark GM, Osborne K, Allred DC: Estrogen receptor status by immunohistochemistry is superior to the ligandbinding assay for predicting response to adjuvant endocrine therapy in breast cancer. J Clin Oncol 1999, I7:1474-I48I.

22. Yaziji $H$, Taylor $C R$ : Begin at the beginning, with the tissue! The key message underlying the ASCO/CAP Task-force Guideline Recommendations for HER2 testing. Appl Immunohistochem Mol Morphol 2007, 1 5:239-24I.

23. Tanner M, Gancberg D, Di Leo A, Larsimont D, Rouas G, Piccart MJ, Isola J: Chromogenic in situ Hybridization. A practical alternative for fluorescence in situ hibridization to detect HER-2/ neu oncogene amplification in archival breast cancer samples. Am J Pathol 2000, 157:1467-72.

24. Yamauchi C, Hasebe T, Iwasaki M, Imoto S, Wada N, Fukayama M, Ochiai A: Accurate assessment of lymph vessel tumor emboli in invasive ductal carcinoma of the breast according to tumor areas, and their prognostic significance. Hum Pathol 2007, 38:247-259.

25. Carter CL, Allen C, Henson DE: Relation of tumor size, lymph node status and survival in $\mathbf{2 4 , 7 4 0}$ breast cancer cases. Cancer 1989, 63:18|-187.

26. Rivadeneira DE, Simmons RM, Christos PJ, Hanna K, Daly JM, Osborne MP: Predictive Factors associated with Axillary Lymph Node Metastases in T I a and T I b Breast Carcinomas: Analysis in More Than 900 Patients. J Am Coll Surg 2000, 191:1-6.

27. Arnaout-Alkarain A, Kahn HJ, Narod SA, Sun PA, Marks AN: Significance of lymph vessel invasion identified by the endothelial lymphatic marker D2-40 in node negative breast cancer. Mod Pathol 2007, 20: |83-19|.

28. Braun M, Flucke U, Debald M, Walgenbach-Bruenagel G, Walgenbach K-J, Holler T, Polcher M, Wolfgarten M, Sauerwald A, Keyver-Paik M, Kuehr M, Buttner R, Kuhn W: Detection of lymphovascular invasion in early breast cancer by D2-40(podoplanin): a clinically useful predictor for axillary lymph node metastasis. Breast Cancer Res Treat 2008, I I 2(3):503-5II.

29. Tezuka K, Onoda N, Takashima T, Takagaki K, Ishikawa T, Wakasa T, Wakasa K, Hirakawa K: Prognostic significance of lymphovascular invasion diagnosed by lymphatic endothelium immunostaining in breast cancer patients. Oncol Rep 2007, I 7:997-1003.

30. El-Gohary YM, Metwally G, Saad RS, Robinson MJ, Mesko T, Poppiti RJ: Prognostic significance of intratumoral and peritumoral lymphatic density and blood vessel density in invasive breast carcinomas. Am J Clin Pathol 2008, I 29:578-586.

3I. Ito M, Moriya T, Ishida T, Usami S, Kasajima A, Sasano H, Ohuchi N: Significance of Pathological Evaluation for Lymphatic Vessel Invasion in Invasive Breast Cancer. Breast Cancer 2007, 14:38I-387.

32. Chagpar AB, Scoggins CR, Martin RC 2nd, Carlson DJ, Laidley AL, EIEid SE, McGlothin TQ: Prediction of sentinel lymph node-only disease in women with invasive breast cancer. Am J Surg 2006, 192:882-887.

33. Leidenius MHK, Vironen JH, Riihelä MS, Krogerus LA, Toivonen TS, von Smitten KAJ, Heikkilä PS: The prevalence of non-sentinel node metastasis in breast cancer patients with sentinel node micrometastasis. EJSO 2005, 31:13-18. 
34. Choi SH, Barsky SH, Chang HR: Clinicopathologic Analysis of Sentinel Lymph Node mapping in early breast cancer. Breast J 2003, 9:153-162.

35. Viale G, Zurrida S, Maiorano E, Mazzarol G, Pruneri G, Paganelli G, Maisonneuve $P$, Veronesi $U$ : Predicting the status of axillary sentinel lymph nodes in $\mathbf{4 3 5} I$ patients with invasive breast carcinoma treated in a single institution. Cancer 2005, 1 03:492-500.

36. Colleoni M, Rotmensz N, Maisonneuve P, Sonzogni A, Pruneri G, Casadio C, Luini A, Veronesi P, Intra M, Galimberti V, Torrisi R, Andrighetto S, Ghisini R, Goldhirschi A, Viale G: Prognostic role of the extent of peritumoral vascular invasion in operable breast cancer. Annals of Oncology 2007, 18: I632-1640.

37. Bono P, Wasenius V-M, Heikkila P, Lundin J, Jackson DG, Joensuu H: High LYVE-I-Positive Lymphatic Vessel Numbers Are Associated with Poor Outcome in Breast Cancer. Clinical Cancer Research 2004, 10:7144-7|49.

38. Rabban JT, Chen YY: D2-40 expression by breast myoepithelium:potential pitfalls in distinguishing intralymphatic carcinoma from in situ carcinoma. Human Pathology 2008, 39:175-183.

39. Auwera I Van der, Cao Y, Tille JC, Pepper MS, Jackson DG, Fox SB, Harris AL, Dirix LY, Vermeulen PB: First international consensus on the methodology of lymphangiogenesis quantification in solid human tumours. Br J Cancer 2006, 95: I6 I I-1625.

40. Gasparini G: Prognostic value of vascular endothelial growth factor in breast cancer. Oncologist 2000, 5(Suppl I):37-44.

4I. Fridman V, Humblet C, Bonjean K, Boniver J: Assessment of tumor angiogenesis in invasive breast carcinomas: absence of correlation with prognosis and pathological factors. Virchows Arch 2000, 437:6II-617.

42. Ludovini V, Sidoni A, Pistola L, Bellezza G, de Angelis V, Gori S, Mosconi AM, Bisagni G, Cherubini R, Bian AR, Rodinò C, Sabbatini R, Mazzocchi B, Bucciarelli E, Tonato M, Colozza M: Evaluation of the prognostic role of vascular endothelial growth factor and microvessel density in stages I and II breast cancer patients. Breast Cancer Res Treat 2003, 8I:159-I68.

43. Nicolini A, Campani D, Miccoli P, Spinelli C, Carpi A, Menicagli M, Ferrari P, Gadducci G, Rossi G, Fini M, Giavaresi G, Bonazzi V, Giardino R: Vascular endothelial growth factor (VEGF-A) and other common tissue prognostic indicators in breast cancer: a case-control study. Int I Biol Markers 2004, I 9:275-28I.

44. Mylona E, Alexandrou P, Mpakali A, Giannopoulou I, Liapis G, Markaki $S$, Keramopoulos A, Nakopoulou $L$ : The prognostic value of vascular endothelial growth factors (VEGF-As)-A and $B$ and their receptor, VEGF-AR-I, in invasive breast carcinoma. Gynecol Oncol 2007, 104:557-563.

45. Evangelou E, Kyzas PA, Trikalinos TA: Comparison of the diagnostic accuracy of lymphatic endothelial markers: Bayesian approach. Mod Pathol 2005, I 8: |490-|497.

46. Vermeulen PB, Gasparini G, Fox SB, Fox SB, Colpaert C, Marson LP, Gion M, Belien JA, de Waal RM, Van Marck E, Magnani E, Weidner N, Harris $A L$, Dirix LY: Second international consensus on the methodology and criteria of evaluation of angiogenesis quantification in solid tumours. Eur J Cancer 2002, 38: I564-I579.

47. Weidner N: Current pathologic methods for measuring intratumoral microvessel density within breast carcinoma and other solid tumors. Breast Cancer Res Treat 1995, 36:169-180.

\section{Pre-publication history}

The pre-publication history for this paper can be accessed here:

http://www.biomedcentral.com/1471-2407/9/109/pre pub
Publish with Biomed Central and every scientist can read your work free of charge

"BioMed Central will be the most significant development for disseminating the results of biomedical research in our lifetime. "

Sir Paul Nurse, Cancer Research UK

Your research papers will be:

- available free of charge to the entire biomedical community

- peer reviewed and published immediately upon acceptance

- cited in PubMed and archived on PubMed Central

- yours - you keep the copyright
BioMedcentral 